\title{
PLC Based Multi-Product Vending Machine
}

\author{
D Sridhar Raja, Abinethri. R, T.Vijayan
}

\begin{abstract}
The vending machine is a kind of cash driven machine that automatically distributes snacks, drinks and other consumer products automatically. Consumer pay coin into a slot, once a choice is made by pressing the push button, the machine dispenses the item purchased. Money, card or coin-based product vending machine by using embedded microcontrollers; Arduino and Raspberry Pi are currently used in systems. By using these microcontrollers, it is complicated when there was a technical error. In this project, we have created a multi-product coin type vending machine by using Mitsubishi PLC. The Programming Logic Controller $(P L C)$ used automatically to monitor and control with high speed, efficiency, and reliability. Switch $O N$ the power supply. Put the coin in the coin acceptor, and then select the product by pressing push button. The motor starts rotating along with the spring and moves the selected item until it released from the spring. The Hall Effect sensor used to count the rotation with the help of the magnet to sense. When the product released from the spring the motor stop rotating and the released product is ready to dispense. The drawback of the project is the vending machine cannot detect fake coins and the consumer cannot refund the money if they slot a coin when there is no product in the machine. [1],[ 3],[5]
\end{abstract}

Keywords : Hall effect sensor, DC motor, coin acceptor, PLC(Programmable Logic Controller).

\section{INTRODUCTION}

A vending machine is a type of money based machine that distributes products quickly and automatically. In 1880, the first selling machine in Egyptian temples was set up for dispensing water in return of coins discovered by the Greek mathematician and engineer Heron of Alexandria. There are various types of product vending machines such as snacks, tickets, etc. There are more than 25 individual vending machines. Dubai Mall found the first gold seller Gold to Go vending machine in the United Arab Emirates. This machine is protected by armored gaurds. This ATM splits out 24 carat gold in 320 different styles: gold bars, coins and jewelry. [2 ], [ 4],[6]

Nowadays, most product vending machines use microcontrollers, arduino and raspberry pi. By using these controllers, programming is very difficult when the product is expanding. PLC compared with, the microcontroller will perform limited and less work operations. [19],[20],[21]The microcontroller cannot directly communicate with high power

Revised Manuscript Received on July 22, 2019.

* Correspondence Author

Sridhar Raja D Department of EIE, Bharath Institute of Higher Education and Research, Tamilnadu, India. Email: sridharraja.eie@bharathuniv.ac.in and research, Tamilnadu, India. Email: abi.eie@ bharathuniv.ac.in

T.Vijayan, Department of EIE, Bharath Institute of Higher education and research, Tamilnadu, India. Email: vijayan.eie@bharathuniv.ac.in
R.Abinethri, Department of EIE, Bharath Institute of Higher education

and has a complex structure. A microcontroller only performed with limited number of executions simultaneously and is usually used on micro devices. Microcontrollers cannot communicate with all protocols and the MC's scan rotation time is slow.

Therefore, we have created a number of product coin type vending machine by interacting with the Mitsubishi PLC. The Programming Logic Controller (PLC) is used to automate the machine by operating switches, sensors and motors. Compared with other microcontrollers, PLC programming and the development time is limited. In PLC, I / O capacity and memory are higher than microcontrollers. Processing time is faster than other microcontroller. PLC will communicate with various protocols and will be reliable with any applications. PLC can also work in the hazardous area, but the microcontrollers cannot work. The advantage of the PLC is that it can work in both AC as well as in DC. Failure is less likely to be compared to other controllers. [7], [9] ,[11]

\section{PlC(Programmable logic Controller)}

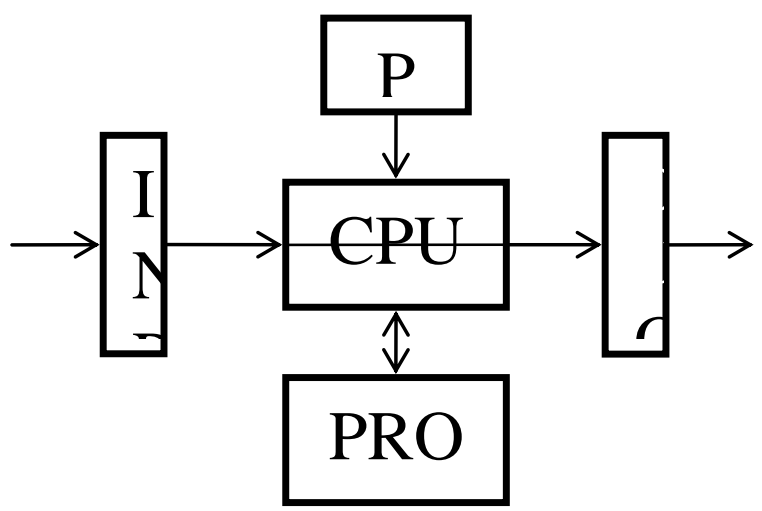

Fig.1.Block Diagram of PLC

A programmable rationale controller (PLC) is an uncommon type of microchip based control, which jelly programmable memory guidelines and controls machines and procedures to execute rationale, arranging, timing, estimation, and science. These control frameworks are exceptionally intended to get by in cruel situations and ensure against warmth, cold, residue and dampness. They are fundamentally used to control computerized frameworks in the business. Presently they are the most progressive and more straightforward control frameworks that are currently vigorously supplanting the harder wire bend transfers. There are two kinds of PLC hand-off sort and transistor type. Transistor type PLC is utilized uniquely for rapid engines. We use FX1N 14MR PLC with 8 data sources and 6 transfer yields. 


\section{FLOWCHART}

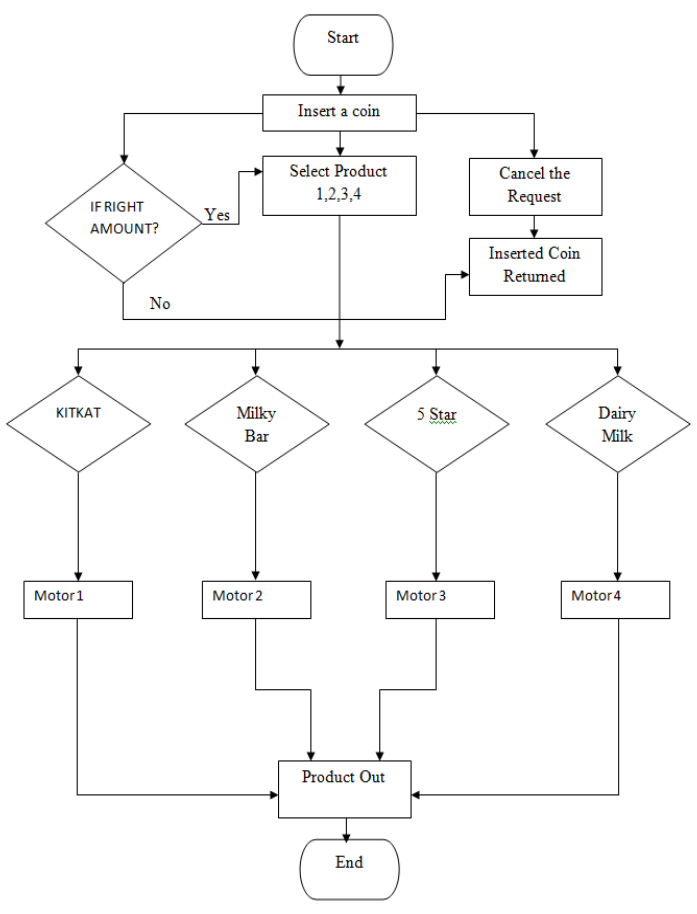

Fig.2.Diagram of Flow Chart

\section{BLOCK DIAGRAM}

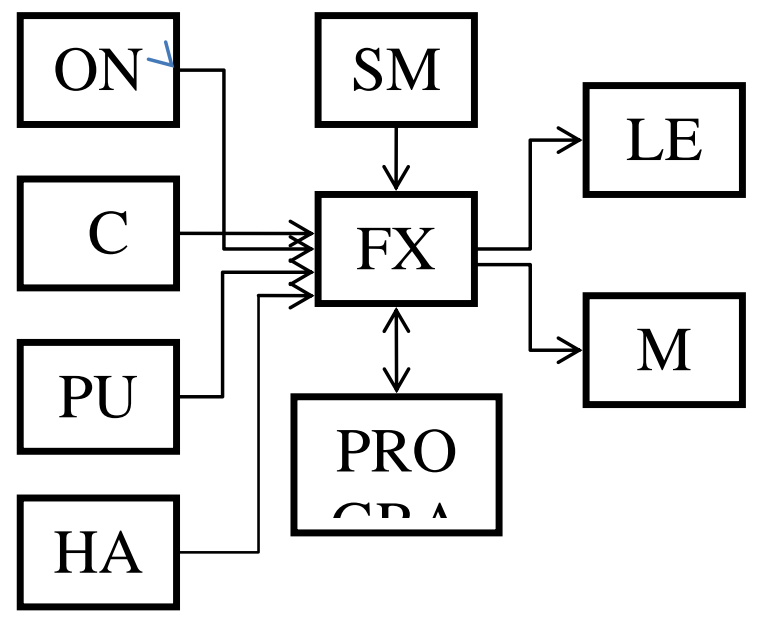

Fig.3. .Block Diagram of Vending Machine

Information sources supplant constant simple power sign to advanced electrical sign, and these sign are applied to the PLC by means of connector.These information sign are put away in PLC outer memory. This is finished by the CPU.Control rationale or program calculations are written in the programming gadget and put away in client memory. [14],[ 16], [18]The CPU gets these directions from client memory and empowers information flag through controlling, registering, and handling by initiating them to control yield devices.Execution of the outcome is put away in outside memory that controls the yield drives.CPU has a beware of yield flag and continues refreshing the substance of information memory as indicated by changes in yield memory. [8],[10], [12]

\section{FINISHED HARDWARE KIT}

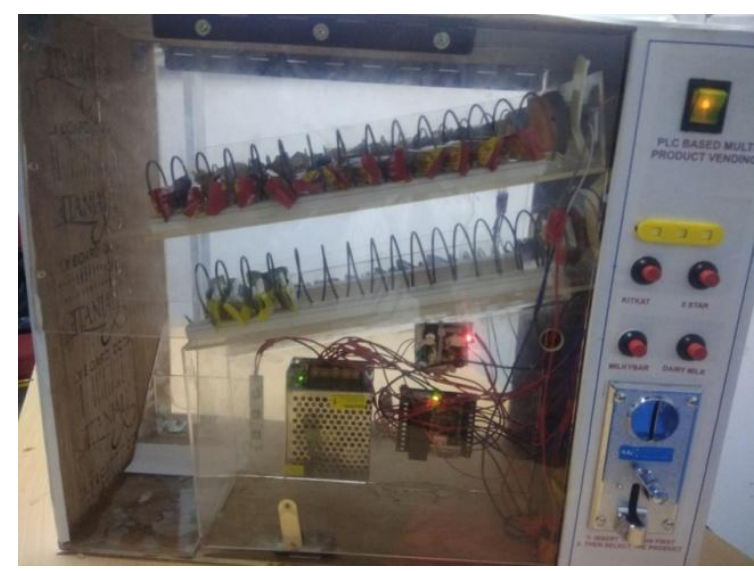

Fig.4.Front Side of Vending Machine

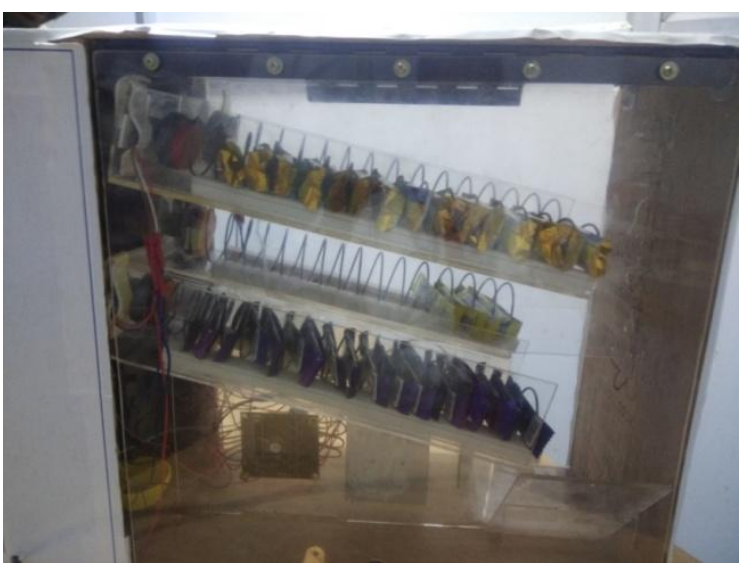

Fig.5.Back Side of Vending Machine

\section{ALgORITHM}

i) Switch ON the power supply.

ii) The LED blinks when we slot a coin in the coin acceptor.

iii) Then select the product by pressing the push button and the motor is ON.

iv) The motor will rotate along with the spring to move the selected product.

v) The rotation of the spring is counted by the sensor with the help of the magnet to sense.

vi) The motor will be OFF when the selected product is ready for dispense. [13], [15], [17]

\section{CONCLUSION}

In this project, we use PLC as a controller and got an expected output for the multi-product vending machine. The design of the vending machine described only four types of products and the number can be further increased. The operation of the vending machine was based on the coin acceptor, and four different motors moving items out. The fake coin detection can also be developed in the earlier system. In the future, we planned to enhance this project to HMI based multi-product vending machine. We can also use smart cards and QR code based transactions.

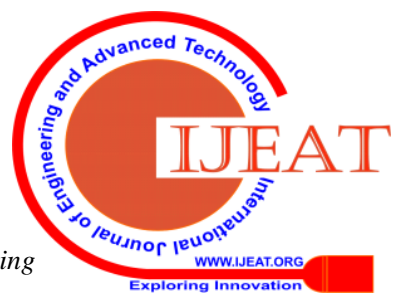




\section{REFERENCES}

[1] Sharma, R.K., Irusapparajan, G. \& Periyaazhagar, D. 2019, "Three-phase symmetric cascading Z-source seven levels multileve inverter excited by multi carrier sinusoidal pulse width modulation scheme", International Journal of Innovative Technology and Exploring Engineering, vol. 8, no. 10, pp. 4269-4274

[2] Velavan, R., Bharanidharan, S. \& Sheeba, B. 2019, "EMF pollution Causes, effects and protection", International Journal of Innovative Technology and Exploring Engineering, vol. 8, no. 9 Special Issue 3, pp. 1166-1168.

[3] Saravana, S., Balaji, S., Arulselvi, S. \& John Paul Praveen, A. 2019, "Reliable power quality monitoring and protection system", International Journal of Innovative Technology and Exploring Engineering, vol. 8, no. 9 Special Issue 3, pp. 644-645.

[4] Tamil Selvan, S. \& Sundararajan, M. 2019, "Performance Parameters of 3 Value 8t Cntfet Based Sram Cell Design Using H-Spice", International Journal of Recent Technology and Engineering, vol. 8, no. 2 Special issue 5, pp. 22-27.

[5] Jac Fredo, A.R., Abilash, R.S., Femi, R., Mythili, A. \& Kumar, C.S 2019, "Classification of damages in composite images using Zernike moments and support vector machines", Composites Part B: Engineering, vol. 168, pp. 77-86

[6] Kathiravan, P. \& Govindaraju, C. 2019, "Design and evaluation of ultra gain isolated DC-DC converter for photovoltaic system", International Journal of Engineering and Advanced Technology, vol. 8, no. 5, pp. 2646-2651.

[7] Kripa, N., Vasuki, R. \& Kishore Kanna, R. 2019, "Realtime neural interface controlled au-pair BIMA bot", International Journal of Recent Technology and Engineering, vol. 8, no. 1, pp. 992-994.

[8] Mohanraj, Meenaa Kumari, M., Philomina, S. \& Jasmin, M. 2019 "In-situ humidity measurement of hydrogen fuel cell car using MEMS sensor", International Journal of Recent Technology and Engineering, vol. 8, no. 1, pp. 41-43.

[9] Velmurugan, T. \& Prakash, S. 2019, "Artificial intelligent based distribution automation of swift fault detection isolation and power restoration for HT network", International Journal of Innovative Technology and Exploring Engineering, vol. 8, no. 6, pp. 1-6.

[10] Dwarakesh, K. \& Prem Kumar, G. 2019, "Five-level inverter based sequential boost system using fuzzy logic controller", International Journal of Innovative Technology and Exploring Engineering, vol. 8, no. 6, pp. 12-19.

[11] Anne Gifta, A. \& Hemavathi, G. 2019, "Analysis of grid tied solar PV system using ANFIS Algorithm", International Journal of Innovative Technology and Exploring Engineering, vol. 8, no. 6, pp. 312-316.

[12] Jayavel, R., Rangaswamy, T.R. \& Prakash, S. 2019, "Efficient grid management system with renewable and conventional power sources", International Journal of Innovative Technology and Exploring Engineering, vol. 8, no. 6, pp. 287-289.

[13] Hemavathi, G. \& Maheshwaran, S. 2019, "Proportional resonant controlled high gain step-up converter system with improved response", International Journal of Innovative Technology and Exploring Engineering, vol. 8, no. 6, pp. 317-323.

[14] Periyaazhagar, D. \& Irusapparajan, G. 2019, "Design and completion of asymmetric single phase 27 level cascaded mli for various pwm scheme", International Journal of Innovative Technology and Exploring Engineering, vol. 8, no. 6, pp. 792-797.

[15] Mahalakshmi, V. \& Vijayaragavan, S.P. 2019, "PV based power electronic converters for high voltage DC applications", International Journal of Recent Technology and Engineering, vol. 7, no. 6, pp. 670-674.

[16] Irusapparajan, G., Periyaazhagar, D., Prabaharan, N. \& Rini Ann Jerin, A. 2019, "Experimental verification of trinary DC source cascaded h-bridge multilevel inverter using unipolar pulse width modulation", Automatika, vol. 60, no. 1, pp. 19-27.

[17] Sangeetha, G., Sherine, S., Arputharaju, K. \& Prakash, S. 2019, "On Line Monitoring of Higher Rated Alternator using Automated Generator Capability Curve Administer", Proceedings of the IEEE International Conference on \&amp;quot;Recent Trends in Electrical, Control and Communication\&amp;quot;, RTECC 2018, pp. 176.

[18] Bycil, V.J. \& Wiselin, M.C.J. 2019, "Modeling and analysis of vibration energy harvesting system using piezo stack", International Journal of Mechanical and Production Engineering Research and Development, vol. 9, no. Special Issue 1, pp. 523-533.

[19] Sripada, A., Warrier, A., Kapoor, A., Gaur, H. \& Hemalatha, B. 2018, "Dynamic lateral balance of humanoid robots on unstable surfaces", International Conference on Electrical, Electronics, Communication
Computer Technologies and Optimization Techniques, ICEECCOT 2017 , pp. 539.

[20] Srinivasan, S., Thirumalaivasan, K. \& Sivakumaran, T.S. 2018 "Performance evaluation of double-output luo converters", Journal of Advanced Research in Dynamical and Control Systems, vol. 10, no. 10 Special Issue, pp. 870-878.

[21] Karthikayen, A. \& Selvakumar Raja, S. 2018, "A skellam distribution inspired trust factor-based selfish node detection technique in MANETs", Journal of Advanced Research in Dynamical and Control Systems, vol. 10, no. 13, pp. 940-949.

\section{AUTHORS PROFILE}

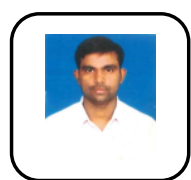

D.Sridhar Raja, Assistant Professor, Department of EIE,Bharath Institute of Higher education and research, Tamilnadu, India

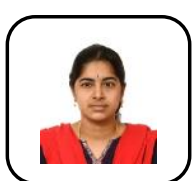

R.Abinethri, Assistant Professor, Department of EIE,Bharath Institute of Higher education and research, Tamilnadu, India

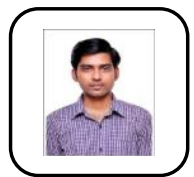

T.Vijayan, Assistant Professor, Department of EIE,Bharath Institute of Higher education and research, Tamilnadu, India 